\title{
Quality of life assessment in patients with chronic urticaria *
}

\section{Estudo da qualidade de vida nos pacientes com urticária crônica}

\author{
Ana Paula Fusel de Ue ${ }^{1}$ \\ Osmar Rotta ${ }^{2}$ \\ Amanda Rodrigues Miranda de Lima ${ }^{4}$
}

\author{
Patrícia Karla de Souza ${ }^{1}$ \\ Wellington de Jesus Furlani ${ }^{3}$ \\ Dominique Sanda Oliveira Vilarinho Sabbag ${ }^{4}$
}

\begin{abstract}
BACKGROUND: Chronic urticaria affects patients by interfering with their daily activities, damaging their self-esteem and negatively affecting their interpersonal relationships. Healthcare professionals may underestimate the impact of the condition on patients' quality of life.

OвJECTIVES: To evaluate quality of life using one generic and one disease-specific health-related quality of life instrument; to compare quality of life between the different clinical types of chronic urticaria and to evaluate whether angioedema further impairs quality of life. METHODS: Sixty-two patients with chronic urticaria, who had had signs or symptoms of the disease within the preceding week, were divided into groups according to whether they had ordinary chronic urticaria, physical chronic urticaria or mixed chronic urticaria. ResulTs: There was a predominance of women in this study (72.6\%). The mean age of patients was 39.8 years and angioedema was associated with chronic urticaria in $75.8 \%$ of cases. Associated angioedema was more commonly found in patients with ordinary chronic urticaria $(\mathrm{p}=0.011)$ and in women $(\mathrm{p}=0.024)$. With respect to the different clinical types, $32.3 \%$ of the patients had ordinary chronic urticaria, $27.4 \%$ had physical chronic urticaria and $40.3 \%$ had mixed chronic urticaria. Mean overall score for the disease-specific questionnaire was 10.4. In this questionnaire, the most affected domains were "symptoms and feelings" and "daily activities", while the most affected domains in the SF-36 were "physical role" and "vitality". Quality of life was found to be impaired in women, in patients of up to 30 years of age, in those attending a first consultation, in those with higher education levels, in patients who had had the disease for up to one year and in those with angioedema.

Conclusions: Chronic urticaria affects quality of life, as measured using a disease-specific questionnaire and a generic questionnaire. There was no statistically significant difference between the clinical types. The presence of angioedema impaired patients' quality of life even further. There was a statistically significant correlation between the scores obtained using the disease-specific questionnaire and those obtained using the generic questionnaire.
\end{abstract}

Keywords: Angioedema; Quality of life; Questionnaires; Sickness impact profile; Urticaria

Resumo: FundAMENTOS: A urticária crônica compromete o doente por interferir nas atividades diárias, prejudicar a autoestima e as relações interpessoais. Os profissionais de saúde subestimam seu impacto na qualidade de vida dos doentes.

OвJETIvos: Avaliar a qualidade de vida com questionário específico e genérico. Compará-la entre os tipos clínicos de urticária crônica e avaliar se o angioedema piora a qualidade de vida.

MÉTODOs: Participaram 62 doentes com urticária crônica, com sinais e sintomas da doença até 7 dias da consulta, que foram divididos em urticária crônica comum, urticária crônica física e urticária crônica mista.

RESultados: Observou-se predominância de mulheres (72,6\%), idade média de 39,8 anos, angioedema associado em 75,8\% dos doentes. Apresentaram mais angioedema doentes com urticária crônica comum $(p=0,011)$ e mulheres $(p=0,024)$. Quanto aos tipos clínicos, 32,3\% apresentaram urticária crônica comum, 27,4\% urticária crônica física e 40,3\% urticária crônica mista. O escore médio total do questionário específico foi 10,4. No questionário específico, os domínios mais comprometidos foram "Sintomas e sentimentos" e "Atividades diárias", e, no SF-36, "Aspectos físicos" e "Vitalidade". Houve comprometimento da qualidade de vida nas mulheres, nos doentes com até 30 anos, em primeira consulta, nos mais escolarizados, naqueles com até 1 ano de doença e naqueles com angioedema.

CONCLusõEs: A urticária crônica compromete a qualidade de vida medida pelos questionários específico e genérico. Não houve diferença estatisticamente significante na qualidade de vida entre os tipos clínicos. A presença do angioedema conferiu pior qualidade de vida aos doentes. Houve correlação estatisticamente significante entre os escores do questionário específico e do questionário genérico.

Palavras-chave: Angioedema; Perfil de impacto da doença; Qualidade de vida; Questionários; Urticária

Received on 27.06.2010.

Approved by the Advisory Board and accepted for publication on 17.10.2010.

* Study conducted at the Dermatology Department, Escola Paulista de Medicina, Federal University of São Paulo (UNIFESP), São Paulo, Brazil. Conflict of interest: None / Conflito de interesse: Nenbum

Financial funding: None / Suporte financeiro: Nenhum

Master's degree in Dermatology from the Escola Paulista de Medicina, Federal University of São Paulo (UNIFESP). Collaborating physician at the Immunological/Environmental Dermatosis/Urticaria Outpatient Clinic, Department of Dermatology, Escola Paulista de Medicina, Federal University of São Paulo (UNIFESP), São Paulo, Brazil.

PhD. Associate Professor of General Dermatology. Head of the Department of Dermatology, Escola Paulista de Medicina, Federal University of São Paulo (UNIFESP), São Paulo, Brazil.

Dermatologist, Escola Paulista de Medicina, Federal University of São Paulo (UNIFESP). Collaborating physician at the Immunological/Environmental Dermatosis/Urticaria Outpatient Clinic, Department of Dermatology, Escola Paulista de Medicina, Federal University of São Paulo (UNIFESP), São Paulo, Brazil. Dermatologist. Collaborating physician at the Immunological/Environmental Dermatosis/Urticaria Outpatient Clinic, Department of Dermatology, Escola Paulista de Medicina, Federal University of São Paulo (UNIFESP), São Paulo, Brazil. 


\section{INTRODUCTION}

Urticaria is a common disease that is characterized by transient pruriginous wheals that may be accompanied by angioedema. ${ }^{1,2}$ Diagnosis is eminently clinical and meticulous anamnesis is essential to establish the clinical form of the disease and the possible causative agent. ${ }^{3,4}$

The condition is considered chronic when wheals are present on a daily or almost daily basis for a period exceeding six weeks. ${ }^{1,25-7}$ In this form, the disease often interferes with the patient's routine activities, damaging his/her self-esteem and negatively affecting interpersonal relationships. ${ }^{6,8}$

Since the course of the disease is benign from a clinical point of view and it is non-life threatening, with transitory lesions and temporary disfigurement, healthcare professionals often underestimate the impact of chronic urticaria on patients' quality of life. ${ }^{9}$

Currently, there appears to be a trend in the medical literature towards recognizing and understanding the impact of skin diseases on patients' quality of life. In recent decades, various instruments have been developed to measure quality of life in dermatology with the objective of evaluating patients' progress and understanding in what ways the disease affects them. ${ }^{10-13}$

The impact of a disease on quality of life may not be directly related to its clinical severity but rather with the resulting stigmatization and the discomfort it causes, reinforcing the importance of quality of life studies in dermatology. ${ }^{11,14}$

Studies have shown that the degree to which quality of life is affected in patients with chronic urticaria may vary in accordance with the different clinical types of the disease, and may in some aspects even become disabling. ${ }^{15}$ The degree to which quality of life is impaired in these patients was found to be similar to that experienced by coronary patients with triple vessel coronary artery disease, principally with respect to psychological aspects and social relationships. ${ }^{9}$

The objective of the present study was to assess the impact of chronic urticaria on patients' quality of life and to clarify which domains were more severely affected in these patients. To do so, two questionnaires were applied that had already been validated and culturally adapted for use in Brazil: the Medical Outcomes Study 36-item short-form health survey (SF36), a generic instrument, and the Dermatology Life Quality Index (DLQI) a disease-specific instrument. ${ }^{16,17}$ Whereas the DLQI deals with quality of life by directly addressing the components that are most likely to be affected in patients with skin diseases, the SF36 deals with quality of life generically, incorporating all the domains considered important in measuring the general concept of quality of life.

\section{MATERIAL AND METHODS}

The sample consisted of male and female patients of 18 years of age or more, diagnosed with chronic urticaria associated or not with angioedema, who were selected at the urticaria outpatient clinic of the Dermatology Department, Escola Paulista de Medicina (EPM), University of São Paulo (UNIFESP), São Paulo, Brazil. The study was approved by the institution's internal review board under reference number 0526/07.

Sixty-two patients with chronic urticaria were evaluated and classified into three groups in accordance with an adapted version of the clinical classification established by Grattan et al. ${ }^{3}$ :

Chronic ordinary urticaria (COU) $(n=20)$

Physical urticaria (PU) $(\mathrm{n}=17)$

Mixed urticaria (MU) $(n=25)$, a definition established in this study to define patients in whom the two forms of urticaria (COU and PU) coexisted.

Patients in whom lesions had not been present over the preceding week, those with a diagnosis of acute urticaria, contact urticaria, urticarial vasculitis, angioedema without wheals, patients unable to understand the terms of the study and to provide their written consent to participate and patients with associated clinical and/or psychiatric comorbidities were not included in the study.

Participation was voluntary following consultation at the outpatient urticaria clinic and after the patient had signed an informed consent form. Patients with university education read and answered the questionnaires independently. The investigator was available throughout the entire time to answer any questions. In the case of patients with other levels of education, the investigator read the questions aloud and ticked the participants' answers in the questionnaires. It should be emphasized that both questionnaires permit this form of application, although it is known that it may affect the answers obtained.

Portuguese language versions of the SF-36 and DLQI were used. ${ }^{16,17}$ The SF-36 is a generic instrument that evaluates quality of life over the previous four weeks. The questionnaire was developed by Ware and Sherbourne in 1992. It is simple to administer and consists of 36 questions grouped into eight domains: Physical Functioning, Role-Physical, Bodily Pain, General Health, Vitality, Social Functioning, Role-Emotional and Mental Health. ${ }^{18}$ Each domain is awarded its own score, which ranges from 0 to 100 in which 0 represents the poorest state of health and 100 the best state. The lower the score, the more the individual's quality of life is affected. 
The DLQI is a questionnaire used specifically in dermatology, which was developed by Finlay and Khan in 1994. It is designed to measure the impact of skin conditions on quality of life. ${ }^{10}$ It is composed of ten questions, which can be subdivided into six domains: symptoms and feelings, daily activities, leisure, work/school, personal relationships and treatment. It may be interpreted as a total score or in accordance with the scores of each individual domain. The total DLQI score is calculated from the sum of the scores awarded to each question and ranges from 0 to 30 in which 0 represents the best state of health and 30 the poorest state. The higher the score, the more the quality of life of the individual is affected. This questionnaire evaluates quality of life over the previous seven days, a period that is sufficiently short so as to facilitate recall. Authorization to use the questionnaire was obtained from its authors. $\left[{ }^{1}\right]$

The data were analyzed using the SPSS statistical software program, version 10.0. Descriptive analysis was used for the clinical and demographic characteristics of the patients studied, while the chi-square test was used to compare categorical data, Student's ttest was used to compare two independent means and analysis of variance (ANOVA) was used to compare three or more independent means, together with Tukey's test for multiple comparisons. Spearman's correlation coefficient (r) was used to evaluate the association between the continuous variables. Probability $(p)<0.05$ was used to indicate statistical significance.

\section{RESULTS}

\section{Sociodemographic data and clinical types of chronic urticaria}

Sixty-two patients were enrolled to this study. The mean age of the patients was $39.8 \pm 12$ years (mean \pm SD) and the majority (72.6\%) was female. Only a small percentage of these patients $(17.7 \%)$ had university education. With respect to the duration of the disease as reported by the patients themselves, $32.3 \%$ were found to have had the condition for $1-5$ years, while $30.6 \%$ reported having had urticaria for more than five years. Patients included those attending their first consultation and those who were already being followed up prior to the study. More than half the patients (51.6\%) were attending their first consultation (Table 1).

With respect to the clinical types of chronic urticaria, $32.3 \%$ of patients had COU, while $27.4 \%$ had PU and the majority (40.3\%) had MU (Table 1).

There was no statistically significant difference between the three clinical types with respect to age,
TABLE 1: General characteristics of the 62 patients and the frequency of the three clinical types of chronic urticaria

\begin{tabular}{ll}
\hline $\begin{array}{l}\text { Age (SD/range) (years) } \\
\leq 30 \text { years (\%) }\end{array}$ & $39.8 \pm 12 / 18-74$ \\
$31-45$ years (\%) & 25.8 \\
>46 years (\%) & 43.5 \\
Sex & 30.6 \\
Female (\%) & 72.6 \\
Male (\%) & 27.4 \\
Education level & \\
Primary school (\%) & 38.7 \\
Secondary school (\%) & 43.5 \\
University (\%) & 17.7 \\
Duration of the disease & $43.5 \pm 50.8 / 2-256$ \\
(SD/range) (months) & \\
6 weeks - 1 year (\%) & 37.1 \\
1 - 5 years (\%) & 32.3 \\
> 5 years (\%) & 30.6 \\
Time in outpatient clinic & $15.4 \pm 27.3 / 0-136$ \\
(SD/range) (months) & \\
First consultation (\%) & 51.6 \\
1 -20 months (\%) & 24.2 \\
>21 months (\%) & 24.2 \\
Clinical types of chronic urticaria \\
Chronic ordinary urticaria (\%) \\
$\begin{array}{l}\text { Physical urticaria (\%) } \\
\text { Mixed urticaria (\%) }\end{array}$ \\
\hline
\end{tabular}

gender, duration of the disease or duration of followup at the clinic.

Angioedema was associated with the course of chronic urticaria in $75.8 \%$ of patients. The patients with COU were more likely to have angioedema than those with PU $(90.0 \%$ versus $52.9 \% ; \mathrm{p}=0.011)$ and women were more likely to have angioedema than men $(84.4 \%$ versus $52.9 \%$; $=0.024)$.

\section{Evaluation of quality of life}

DLQI: The mean overall score in the DLQI was $10.4 \pm 7.7$. The domains indicative of greater impairment of quality of life were symptoms and feelings $(3.2 \pm 1.9)$ and daily activities $(2.6 \pm 2.3)$ (Table 2$)$.

SF-36: The domains indicative of greater impairment of quality of life were: role-physical $(55.70 \pm 45.60)$ and vitality $(60.20 \pm 27.90)$. The least affected were social functioning $(78.50 \pm 24.00)$ and bodily pain $(68.70 \pm 27.40)$ (Table 2$)$.

\section{Quality of life and clinical types}

No statistically significant differences were found between the three clinical types (COU, PU, MU) in either of the instruments evaluated with respect to quality of life. 
TABle 2: DLQI and SF-36 - Mean scores of the 62 patients with chronic urticaria

\begin{tabular}{ll}
\hline & Mean \pm SD \\
DLQI - Overall score & $10.4 \pm 7.7$ \\
DLQI - Score in each domain & \\
Symptoms and feelings & $3.2 \pm 1.9$ \\
Daily activities & $2.6 \pm 2.3$ \\
Leisure & $1.7 \pm 1.8$ \\
Work/school & $0.7 \pm 1.1$ \\
Personal relationships & $1.5 \pm 2.1$ \\
Treatment & $0.8 \pm 1.1$ \\
SF-36 - Score in each domain & \\
Physical Functioning & $78.50 \pm 24.00$ \\
Role-Physical & $55.70 \pm 45.60$ \\
Bodily Pain & $68.70 \pm 27.40$ \\
General Health & $66.20 \pm 23.70$ \\
Vitality & $60.20 \pm 27.90$ \\
Social Functioning & $64.70 \pm 33.30$ \\
Role-Emotional & $62.40 \pm 45.40$ \\
Mental Health & $62.40 \pm 24.10$ \\
\hline
\end{tabular}

\section{Quality of life and gender}

Quality of life was found to be more affected in women, with statistically significant differences compared to men in the daily activities domain of the DLQI $(p=0.003)$ and in the vitality $(p=0.038)$, roleemotional $(p=0.018)$ and mental health $(p=0.020)$ domains of the SF-36.

\section{Quality of life and age}

In patients of up to 30 years of age, quality of life was only found to be affected in the DLQI, with a statistically significant difference in the daily activities domain $(\mathrm{p}=0.033)$.

\section{Quality of life and education level}

According to both questionnaires, quality of life was better in the case of patients with only primary education. In the DLQI, the domains with statistically significant differences were daily activities $(p=0.017)$ and leisure $(p=0.001)$, as well as the overall score $(p=0.037)$, while in the SF-36, a statistically significant difference was found only in the social functioning domain $(\mathrm{p}=0.029)$.

\section{Quality of life and duration of the disease}

The patients with up to one year of the disease had poorer quality of life scores, with statistically significant differences in the following domains of the DLQI: leisure $(p=0.018)$, personal relationships $(p=0.003)$ and overall score $(p=0.013)$ but only in the social functioning domain of the SF-36 $(p=0.010)$.

\section{Quality of life and duration of follow-up at the outpatient clinic}

Patients attending for their first consultation had poorer quality of life scores compared to the other patients, with statistically significant differences in the following domains of the DLQI: symptoms and feelings $(p=0.001)$, work/school $(p=0.042)$, personal relationships $(p=0.025)$ and overall score $(p=0.004)$, but only in the role-physical domain of the SF-36 $(\mathrm{p}=0.036)$.

\section{Quality of life and angioedema}

The patients with chronic urticaria and angioedema scored worse in the domains of the SF-36 compared to the patients without angioedema, with statistically significant differences for general health $(p=0.002)$, mental health $(p=0.016)$ and vitality $(p=0.050)$. No differences were found in the DLQI.

\section{Correlations}

Table 3 shows the calculations of Spearman's correlations ( $r$ ) between the domains of the DLQI and those of the SF-36. All the statistically significant correlations between the two questionnaires were negative and found to be weak to moderate, with an $\mathrm{r}$ of 0.254 to -0.465 .

\section{DISCUSSION}

Quality of life is an ample and subjective concept that is dependent on a cultural, social and environmental context. It was defined by the World Health Organization as an "individual's perception of their position in life in the context of the culture and value systems in which they live and in relation to their goals, expectations, standards and concerns". ${ }^{19}$

Since it is a multidimensional concept, the term health-related quality of life was coined. This corresponds to a more limited notion of quality of life, encompassing the domains directly associated with states of physical, psychological and social health. ${ }^{20,21}$

Objective measurements of health status are important in defining the degree of health; however, it is the individual's own perception of his/her state of health that reflects their true quality of life. Ability to deal with limitations and disabilities may greatly affect the individual's perception of his/her state of health and consequently his/her satisfaction with life. Therefore, two people with the same state of health may experiment different quality-of-life status. ${ }^{22}$

What makes the study of quality of life original is the fact that it attempts to measure the needs of an individual based on his/her own perceptions, not just the perceptions of their physician. Conditions considered benign by physicians may have an immense repercussion on patients' lives just as diseases that are potentially serious may not exert an immediate effect on the patient's quality of life. Therefore, taking the patients' expectations into consideration in selecting 
TABLE 3: Spearman's correlation between the domains of the DLQI and those of the SF-36 with respect to the 62 patients with chronic urticaria

\begin{tabular}{lllllllll}
\hline & PF & RP & Pain & GH & Vit & Soc F & R Emot & MH \\
\hline \multirow{2}{*}{ Symptoms and feelings } & $\mathrm{r}-0.317$ & -0.426 & -0.355 & -0.465 & -0.333 & -0.441 & -0.236 & -0.357 \\
& $\mathrm{p} 0.012$ & 0.001 & 0.005 & 0 & 0.008 & 0 & 0.065 & 0.004 \\
Daily activities & $\mathrm{r}-0.254$ & -0.341 & -0.299 & -0.344 & -0.382 & -0.234 & -0.217 & -0.314 \\
Leisure & $\mathrm{p} 0.046$ & 0.007 & 0.018 & 0.006 & 0.002 & 0.067 & 0.09 & 0.013 \\
& $\mathrm{r}-0.248$ & -0.358 & -0.295 & -0.410 & -0.274 & -0.401 & -0.205 & -0.270 \\
Work/school & $\mathrm{p} 0.052$ & 0.004 & 0.02 & 0.001 & 0.031 & 0.001 & 0.11 & 0.034 \\
Personal relationships & $\mathrm{r}-0.169$ & -0.385 & -0.258 & -0.280 & -0.164 & -0.260 & -0.184 & -0.167 \\
Treatment & $\mathrm{p} 0.19$ & 0.002 & 0.043 & 0.027 & 0.203 & 0.041 & 0.151 & 0.195 \\
& $\mathrm{r}-0.213$ & -0.465 & -0.12 & -0.342 & -0.245 & -0.333 & -0.23 & -0.344 \\
& $\mathrm{p} 0.096$ & 0 & 0.352 & 0.007 & 0.055 & 0.008 & 0.073 & 0.006 \\
& $\mathrm{r}-0.042$ & -0.366 & -0.258 & -0.281 & -0.316 & -0.298 & -0.165 & -0.155 \\
& $\mathrm{p} 0.752$ & 0.004 & 0.048 & 0.031 & 0.015 & 0.022 & 0.213 & 0.241 \\
\hline
\end{tabular}

$\mathrm{PF}=$ physical functioning $/ \mathrm{RP}=$ role-physical $/ \mathrm{GH}=$ general health $/$ Vit $=$ vitality $/ \mathrm{Soc} \mathrm{F}=$ social functioning $/$

$\mathrm{R}$ Emot $=$ role-emotional $/ \mathrm{MH}=$ mental health

a therapeutic strategy optimizes the doctor-patient relationship. ${ }^{22}$

Skin diseases potentially exert a negative effect on patients' quality of life. ${ }^{21}$ They may impair quality of life to the same degree as more debilitating diseases or those in which the risk to life is greater. The degree of involvement may not correlate with the clinical severity of the disease, but may present as psychological stress, embarrassment, stigmatization or physical discomfort that over time may result in a significant decrease in emotional and social well being and in productivity at school or at work. Altogether, these factors may significantly affect the course of the disease and the patient's response to the proposed therapeutic interventions. Therefore, it is essential that the dermatologic evaluation include measurements of the patients' perception of their well-being in relation to the skin disease, i.e. quality of life assessments. ${ }^{11,23}$

When dealing with the patient with chronic urticaria it is important to emphasize that the cause of the disease may remain undetermined and that response to treatment may be disappointing. ${ }^{6}$ The patient's frustration may result in a decrease in his/her quality of life. The objective of treatment should be to control the chronic urticaria so as to minimize its effect on the patient's quality of life.

The objective of this study was to evaluate the impact of chronic urticaria on patients' quality of life and clarify in which domains patients feel more affected by the disease.

Analysis of the SF-36 and DLQI scores showed that chronic urticaria is a disease that impairs quality of life. Other studies based on the same instruments have shown similar results. ${ }^{15,24-27}$

The patients selected for this study were recruited at a dermatology outpatient clinic specializ- ing in urticaria. The clinic is linked to a university that is a reference in tertiary healthcare. Consequently, it is probable that the degree of morbidity found may be greater and may not be representative of patients with chronic urticaria in the general population. This may justify the greater negative impact on quality of life found in the present study. Furthermore, the majority of the population referred to public healthcare services is generally found to be economically deprived, a situation that may generate variables capable of affecting quality of life, either for the better or for the worse, depending on the aspect analyzed.

Some variance was observed in the comparison between the overall mean score of the DLQI in the present study (10.4) and data published in the literature. The mean scores reported in the literature range from 5.1 to 13.4 . $^{25,28-30}$ The forms of data collection (interview or self-administration, randomized samples, treated or untreated patients) and the cultural differences of the patients studied (education level, subjectivity of the suffering) may explain these differences. In the present study, the most affected domains of quality of life were symptoms and feelings and daily activities. Both represent the areas in which the signs and symptoms of the disease would have the greatest repercussion. The symptoms and feelings domain reflects how pruritus and the presence of wheals may upset or embarrass the patient in front of other people. The daily activities domain shows how chronic urticaria may hamper the patient's daily life or restrict their manner of dressing. These findings are in agreement with data published in the literature. $15,28,30$

In the present study, the SF-36 domains indicative of greater impairment of quality of life were: rolephysical and vitality. The role-physical domain reflects 
the repercussion of possible limitations of physical health in carrying out work-related and daily activities. The vitality domain evaluates the individual's energy level and fatigue. This result was expected, since it shows the extent to which pruritus and the anguish provoked by this condition, as well as the skin lesions, may hamper the patient in carrying out work-related activities, either by reducing the individual's attention level or as a result of the discomfort and irritability these conditions cause. The least affected domains were physical functioning and bodily pain. The physical functioning domain measures the repercussion of possible physical limitations on daily activities such as taking a bath, dressing, walking moderate distances, running, climbing stairs, carrying bags, bending over and kneeling. The bodily pain domain evaluates the effect of possible pain on daily and work-related activities. Therefore, it is expected that these domains would be affected to a lesser extent in chronic urticaria with no other associated comorbidities. Reports in the literature reflect a similar pattern. ${ }^{24,26}$

In the comparison of the scores of the questionnaires between the clinical types of chronic urticaria (COU, PU and MU), no statistically significant differences were found between the various types and it was impossible to conclude whether one may affect quality of life to a greater extent than another. In the literature, O'Donnel et al. (1997) and Poon et al. (1999) described poorer quality of life in patients with delayed pressure urticaria and cholinergic urticaria. 9,15 In both these studies, sample sizes were larger than that of the present study. We believe that a larger sample would permit a similar conclusion to be reached, since in our clinical practice the suffering of the patients with these forms of physical urticaria is perceptible.

Women suffer the impact of chronic urticaria more than men. In the DLQI, a statistically significant difference was found only in the daily activities domain $(p=0.003)$. This domain is composed of questions that evaluate difficulties in going shopping or taking care of the house and to what extent the state of the patient's skin affects his/her choice of clothing. Therefore, it is possible that this domain may involve situations that lead to greater negative repercussions on women. In the SF-36, the effects on quality of life in the vitality, role-emotional and mental health domains were statistically significant $(\mathrm{p}=0.038, \mathrm{p}=0.018, \mathrm{p}=0.020$, respectively $)$. This indicates a possible psychological and emotional vulnerability in women coping with chronic urticaria. The domains that were affected measure the energy and fatigue levels reported by the patients, the repercussion of possible emotional disturbances on the individual's ability to work, and possible states of anxiety and depression. An evaluation of psychiatric comorbidities associated with the patient's dermatological status would be useful to identify whether these results were exclusively a consequence of the repercussions of chronic urticaria on these patients' quality of life.

In the patients of up to 30 years of age, the daily activities domain $(p=0.033)$ of the DLQI was significantly more affected. As this domain includes a question related to clothing, younger patients may feel more severely affected by this limitation compared to older patients.

Patients with a better education level were more affected than those with less schooling. There was a statistically significant difference in the daily activities $(p=0.017)$ and leisure domains $(p=0.001)$ and in the overall score $(p=0.037)$ of the DLQI, as well as in the social functioning domain of the SF-36 $(p=0.029)$. It is possible that better-educated individuals are more affected by pruritus and wheals than individuals with less schooling because they have a better understanding of the situation they are experiencing but are less willing to accept it.

Quality of life was more affected in the patients who had had the disease for up to one year according to both questionnaires, principally in the domains related to social activities and personal relationships. Statistically significant differences were found in the leisure $(p=0.018)$ and personal relationships domains $(p=0.003)$ and in the overall score $(p=0.013)$ of the DLQI and in the social functioning domain of the SF$36(\mathrm{p}=0.010)$, indicating more intense suffering in the case of these patients. These results highlight the degree to which the social life of patients with chronic urticaria is affected: the limitations imposed on their leisure activities because of embarrassment or fear of triggering the disease and the negative effect on their relationships that predisposes them to social isolation. Furthermore, the patient who has had the disease for only a short time is confronting a novel situation and tends to assume a less conformist attitude with respect to the disease.

Patients at their first consultation, i.e. those defined as not being followed up as outpatients at the time of the interview, had poorer quality of life. In the DLQI, the differences were statistically significant both with respect to the overall score $(p=0.004)$ and in the symptoms and feelings $(p=0.001)$, work $/$ school $(p=0.042)$ and personal relationships $(p=0.025)$ domains. The SF-36 revealed significant impairment only in the role-physical domain $(p=0.036)$. Half the present sample consisted of patients attending their first consultation at the urticaria clinic. This suggests that many of these patients still had a poor under- 
standing of how to control the disease, of treatment and of what triggers chronic urticaria. Some were not yet undergoing any treatment at all. This certainly contributed to this negative impact on quality of life.

Angioedema during the course of chronic urticaria resulted in poorer quality of life in these patients. Those with associated angioedema had poorer scores, with statistically significant differences in the general health $(p=0.002)$, mental health $(p=0.016)$ and vitality $(p=0.050)$ domains of the SF36 compared to the patients without angioedema. In a study conducted by Poon et al. (1999) ${ }^{15}$, the association of angioedema with chronic urticaria did not worsen patients' quality of life. Angioedema during chronic urticaria, although benign, is disfiguring. It is understandable that the intense embarrassment caused by this condition could have a negative effect on the patient's quality of life.

All the significant correlations in the DLQI and SF-36 scores were negative, with the majority being weak to moderate. Bearing in mind that the scores of the two questionnaires are read in opposite directions, negative correlations are to be expected. Whereas in the DLQI higher scores represent poorer quality of life, in the SF-36 questionnaire higher scores are indicative of better quality of life. These significant correlations, albeit only moderate to weak, show that both questionnaires deal with the same topic in a complementary way; however, one does not substitute the other. Whereas the DLQI deals with quality of life, focusing more directly on the components that are more likely to be affected in patients with skin diseases, the objective of the SF-36 is to treat quality of life generically, encompassing domains considered important for measuring the general concept of quality of life. The correlations between the questionnaires may be interpreted as a validation test, i.e. to assess whether the SF-36 is appropriate for the measurement of quality of life in patients with skin diseases in various areas.

\section{CONCLUSION}

In recent years, there has been a growing trend towards valuing the patient's perception of the effect of his/her disease on their state of health. Therefore, instruments that evaluate quality of life have emerged as parameters to measure the different components that constitute health status, complementing the traditional parameters of evaluating diseases and treatments. Use of these instruments to measure quality of life should not be restricted to research studies, but should also be considered in routine clinical practice, with a periodic evaluation of the quality of life of patients undergoing outpatient follow-up.

In patients with chronic urticaria, quality of life is negatively affected, as measured by both the DLQI and SF-36 questionnaires. There was no statistically significant difference between the clinical types of the disease. Angioedema during the course of chronic urticaria had a negative effect on patients' quality of life. Quality of life was poorer and this difference was statistically significant in: patients of up to 30 years of age, patients with higher education levels, patients with up to one year of the disease and patients attending their first consultation at the clinic.

The study was based on the observation of different degrees of disability found in patients at the urticaria outpatient clinic of the Dermatology Department, UNIFESP. Some patients, even those with more severe clinical forms of the disease, paid little heed to the pruritus and wheals and did not feel at all stigmatized. On the other hand, other patients reported mild forms of the disease as being restrictive and intolerable. Therefore, it is important to evaluate quality of life in chronic urticaria and principally to understand the perception of these patients in relation to their state of health and to their physical and psychosocial limitations in order to establish optimal humane and pharmacological management in each individual case.

The principal areas in which the quality of life of patients with chronic urticaria is impaired involve psychological aspects and social relationships. A discussion on the possible psychiatric comorbidities associated with chronic urticaria is outside the scope of the present study; however, the need to associate psychological care with skin treatment in certain cases is undeniable, either because of psychological damage resulting from the limitations imposed by chronic urticaria or because of psychiatric comorbidities that may have preceded the skin disease.

Another important objective of the present study was to alert healthcare professionals to these patients. As understanding increases of how chronic urticaria affects quality of life, medical decisions are coming closer to the perspectives of the patients with respect to their disease and its treatment. This broadens the scope of the doctor-patient relationship, consequently rendering it more humane. Therefore, evaluations of quality of life are becoming established as an integral part of treatment; however, further studies are required to fully clarify the pathogenesis of chronic urticaria so that new therapeutic strategies can be developed, reducing the extent to which the quality of life of these patients is impaired by this disease. $\square$ 


\section{REFERENCES}

1. Zuberbier T, Greaves MW, Juhlin L, Kobza-Black A, Maurer D, Stingl G, et al. Definition, classification, and routine diagnosis of urticaria: a consensus report. J Investig Dermatol Symp Proc. 2001;6:123-127.

2. Grattan $\mathrm{CEH}$. The urticaria spectrum: recognition of clinical patterns can help management. Clin Exp Dermatol 2004;29:217-21.

3. Grattan CEH, Sabroe RA, Greaves MW. Chronic urticaria. J Am Acad Dermatol. 2002;46:645-57.

4. Souza PK. Urticária crônica: estudo clínico e laboratorial de 216 casos [tese]. São Paulo: Universidade Federal de São Paulo; 1999.

5. Greaves MW. Pathophysiology of Chronic urticaria. Int Arch Allergy Immunol. 2002;127:3-9.

6. Kozel MMA, Sabroe RA. Chronic Urticaria. Etiology, management and current and future treatment options. Drugs. 2004;64:2515-36.

7. Kaplan AP. Chronic urticaria: pathogenesis and treatment. J Allergy Clin Immunol. 2004;114:465-74.

8. Dibbern Jr DA, Dreskin SC. Urticaria and angioedema: an overview. Immunol Allergy Clin North Am. 2004;24:141-62.

9. O'Donnell BF, Lawlor F, Simpson J, Morgan M, Greaves MW. The impact of chronic urticaria on the quality of life. Br J Dermatol. 1997;136:197-201.

10. Finlay AY, Khan GK. Dermatology life quality index (DLQI) - a simple practical measure for routine clinical use. Clin Exp Dermatol. 1994;19:210-6.

11. Anderson RT, Rajagopalan R. Development and validation of a quality of life instrument for cutaneous disease. J Am Acad Dermatol. 1997:37:41-50.

12. Chren MM, Lasek RJ, Quin LM, Mostow EN, Zyzanski SJ. Skindex, a quality-of-life measure for patients with skin disease: reliability, validity and responsiveness. J Invest Dermatol 1996;107:707-13.

13. Evers AW, Duller P, van der Kerkhof PC, van der Valk PG, der Jong EM, Gerritsen MJ, et al. The impact of Chronic Skin Disease on Daily Life (ISDL): a generic and dermatologic-specific health instrument. Br J Dermatol. 2008;158:101-8.

14. Le Cleach L, Chassany 0 , Levy A, Wolkenstein P, Chosidow 0. Poor reporting of quality of life outcomes in dermatology randomized controlled clinical trials. Dermatology. 2008;216:46-55.

15. Poon E, Seed PT, Greaves MW, Black AK. The extent and nature of disability in different urticarial conditions. Br J Dermatol. 1999;140:667-71.

16. Ciconelli RM, Ferraz MB, Santos W, Meinão I, Quaresma MR. Tradução para a língua portuguesa e validação do questionário genérico de avaliação de qualidade de vida SF-36 (Brasil SF-36). Rev Bras Reumatol. 1999; 39:143-50.

17. Ferraz LB, Almeida FA, Vasconcellos MR, Facina AS, Ciconelli RM, Ferraz MB. The impact of lupus erythematosus cutaneous on the Quality of Life: The BrazilianPortuguese version of DLQI. Qual Life Res. 2006;15:565-70.

18. Ware JE, Sherbourne CD. The MOS 36 Item Short- Form Health Survey (SF-36). Conceptual framework and item selection. Med Care.1992;30:473-83.

19. The World Health Organization Quality of Life assessment (WHOQOL) development and general psychometric properties. Soc. Sci. Med. 1998;46:1569-85.

20. Wilson IB, Cleary PD. Linking clinical variables with health-related quality of life. A conceptual model of patient outcomes. JAMA. 1995;273:59-65

21. Halioua B, Beumont MG, Lunel F. Quality of life in dermatology. Int J Dermatol. 2000;39:801-6.

22. Testa MA, Simonson DC. Assessment of quality of life outcomes. N Engl J Med. 1996;334:835-840.

23. Finlay AY. Quality of life measurement in dermatology: a pratical guide. $\mathrm{Br} J$ Dermatol. 1997;136:305-14.

24. Baiardini I, Giardini A, Pasquali M, Dignetti P, Guerra L, Specchia C, et al. Quality of life and patient's satisfaction in chronic urticaria and respiratory allergy. Allergy. 2003:58:621-3.

25. Grob JJ, Auquier P, Dreyfus I, Ortonne JP. How to prescribe antihistamines for chronic idiopathic urticaria: desloratadina daily vs PRN and quality of life. Allergy. 2009;64:605-12.

26. Ozkan M, Oflaz SB, Kocaman N, Ozseker F, Gelincik A, Büyüköztürk S, et al Psychiatric morbidity and quality of life in patients with chronic idiopathic urticaria. Ann Allergy Asthma Immunol. 2007;99:29-33.

27. Taborda ML, Weber MB, Teixeira KAM, Lisboa AP, Welter EQ. Avaliação da qualidade de vida e do sofrimento psíquico de pacientes com diferentes dermatoses em um centro de referência em dermatologia no sul do país. An Bras Dermatol.2010;85:52-6

28. Thompson AK, Finn AF, Schoenwetter WF. Effect of $60 \mathrm{mg}$ twice-daily fexofenadine $\mathrm{HCl}$ on quality of life, work and classroom productivity, and regular activity in patients with chronic idiopathic urticaria. J Am Acad Dermatol. 2000;43:24-30.

29. Lachapelle JM, Decroix J, Henrijean A, Roquet-Gravy PP, De Swerdt A, Boonen H, et al. Desloratadine $5 \mathrm{mg}$ once daily improves the quality of life of patients with chronic idiopathic urticaria. J Eur Acad Dermatol Venereol. 2006;20:288-92.

30. Mlynek A, Magerl M, Hanna M, Lhachimi S, Baiardini I, Canonica GW et al. The German version of the chronic urticaria quality-of-life questionnaire: factor analysis, validation, and initial clinical findings. Allergy. 2009;64:927-36.

MAILING ADDRESS / ENDEREÇO PARA CORRESPONDÊNCIA:
Ana Paula Fusel de Ue
Avenida Ana Costa, 311 - Cjto 84 - Gonzaga
CEP 11060-OO1 Santos - SP
E-mail: anapaulaue@hotmail.com

How to cite this article/Como citar este artigo: Ue APF, Souza PK, Rotta O, Furlani WJ, Lima ARM, Sabbag DSOV. Quality of life assessment in patients with chronic urticaria. An Bras Dermatol. 2011;86(5):897-904. 